\section{A) Check for updates}

Cite this: Dalton Trans., 2020, 49, 14584

\title{
Phosphinoborane interception at magnesium by borane-assisted phosphine-borane dehydrogenation $\dagger$
}

\author{
Louis J. Morris, ${ }^{a}$ Nasir A. Rajabi, ${ }^{a}$ Michael S. Hill, (D) *a Ian Manners, (D) *b \\ Claire L. McMullin*a and Mary F. Mahon ${ }^{a}$
}

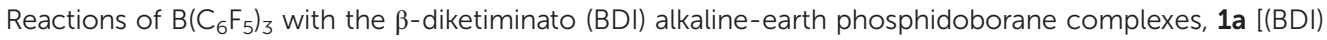
$\left.\mathrm{Ca}\left(\mathrm{H}_{3} \mathrm{~B} \cdot \mathrm{PPh} \mathrm{h}_{2}\right)\right]$ and $\mathbf{1 b}\left[(\mathrm{BDI}) \mathrm{Mg}\left(\mathrm{H}_{3} \mathrm{~B} \cdot \mathrm{PPh}_{2}\right)\right]_{2}\left(\mathrm{BDI}=\left[\mathrm{HC}\left\{\mathrm{C}\left(\mathrm{CH}_{3}\right) \mathrm{N}\left(2,6-i \mathrm{Pr}-\mathrm{C}_{6} \mathrm{H}_{3}\right)\right\}_{2}\right]^{-}\right)$result in the formation of phosphinodiboronate complexes $4 a\left[(B D I) C a\left(\eta^{6}\right.\right.$-toluene $\left.)\left\{\mathrm{H}_{3} B \cdot P P h_{2} \cdot B\left(C_{6} F_{5}\right)_{3}\right\}\right]$ and $4 \mathbf{b} \quad[(B D I) M g$ $\left.\left\{\mathrm{H}_{3} \mathrm{~B} \cdot \mathrm{PPh}_{2} \cdot \mathrm{B}\left(\mathrm{C}_{6} \mathrm{~F}_{5}\right)_{3}\right\}\right]$. Calcium complex $4 \mathrm{a}$ is stable in aromatic solvents at room temperature and does not display well-defined onward reactivity at elevated temperatures. Magnesium complex $\mathbf{4 b}$ undergoes a room temperature transformation to provide the known hydridoborate derivative $3 \mathbf{b}$ [(BDI) $\left.\mathrm{Mg}\left\{\mathrm{HB}\left(\mathrm{C}_{6} \mathrm{~F}_{5}\right)_{3}\right\}\right]$ and an $N, P, N^{\prime}$-ligated species, $5\left[\left\{\mathrm{HC}\left(C\left(\mathrm{CH}_{3}\right) \mathrm{N}\left(2,6-\mathrm{PPr}_{-} \mathrm{C}_{6} \mathrm{H}_{3}\right)\right)_{2}\left(\mathrm{H}_{2} \mathrm{BPPh}\right)\right\} \mathrm{Mg}\left\{\mathrm{H}_{3} \mathrm{~B} \cdot \mathrm{PPh} 2 \cdot \mathrm{B}\left(\mathrm{C}_{6} \mathrm{~F}_{5}\right)_{3}\right\}\right]$ that results from interception of the putative phosphinoborane, $\mathrm{H}_{2} \mathrm{~B}=\mathrm{PPh}_{2}$, by the BDI ligand backbone following $B\left(C_{6} F_{5}\right)_{3}$-mediated hydride abstraction. NMR spectroscopic investigations were supported by DFT calculations, which suggested a mechanism involving $\left.\mathrm{B}_{(} \mathrm{C}_{6} \mathrm{~F}_{5}\right)_{3}$ migration and hydride abstraction within the coordination sphere of magnesium. Interception of $\mathrm{H}_{2} \mathrm{~B}=\mathrm{PPh}_{2}$ by $\mathrm{B}\left(\mathrm{C}_{6} \mathrm{~F}_{5}\right)_{3}$ is proposed to stabilise this species, whilst activating it towards ligand-centred nucleophilic attack. The significant stabilisation energy calculated for the $\mathrm{Ca}-\pi$ (toluene) interaction in $\mathbf{4 a}$ accounts for the contrasting outcomes between the two Ae-elements. The crystal structures of compounds $\mathbf{4 a}$ and $\mathbf{5}$ are presented and discussed.
\end{abstract}

Received 11th September 2020 Accepted 6th October 2020

DOI: $10.1039 / \mathrm{d} 0 \mathrm{dt} 03415 \mathrm{k}$

rsc.li/dalton from the trimethylamine-stabilised monomer (Scheme 1a). ${ }^{12}$ More recently, Manners and co-workers have reported that treatment with stoichiometric quantities of cyclic alkyl amino carbenes (CAACs) induces the dehydrogenative coupling of cessable inorganic materials with contrasting properties to their formally isoelectronic all-carbon analogues. Whereas most polyolefins are highly flammable, polyphosphinoboranes, for example, display flame retardant properties ${ }^{1,2}$ and have seen use as lithographic resists. ${ }^{2-4}$ Although their synthesis, via the catalytic dehydrogenation-polymerisation of phosphine-borane complexes, was first achieved some 20 years ago, catalysts remain almost exclusively based on iron, ruthenium, rhodium or iridium. ${ }^{2-11}$ A metal-free stoichiometric approach was described by Manners, Scheer, and co-workers, who demonstrated the metal-free head-to-tail polymerisation of tert-butylphosphinoborane, which was generated in situ

\footnotetext{
${ }^{a}$ Department of Chemistry, University of Bath, Claverton Down, Bath, BA2 7AY, UK. E-mail:msh27@bath.ac.uk,cm2025@bath.ac.uk

${ }^{b}$ Department of Chemistry, University of Victoria, Victoria, BC V8P 5C2, Canada.

E-mail: imanners@uvic.ca

$\dagger$ Electronic supplementary information (ESI) available: General synthetic experimental details, NMR spectra, X-ray diffraction analysis of compounds $\mathbf{4 a}$ and $\mathbf{5}$, details for the computational analysis and atomic coordinates of computed structures. CCDC 2024757 and 2024758. For ESI and crystallographic data in CIF or other electronic format see DOI: 10.1039/d0dt03415k
}

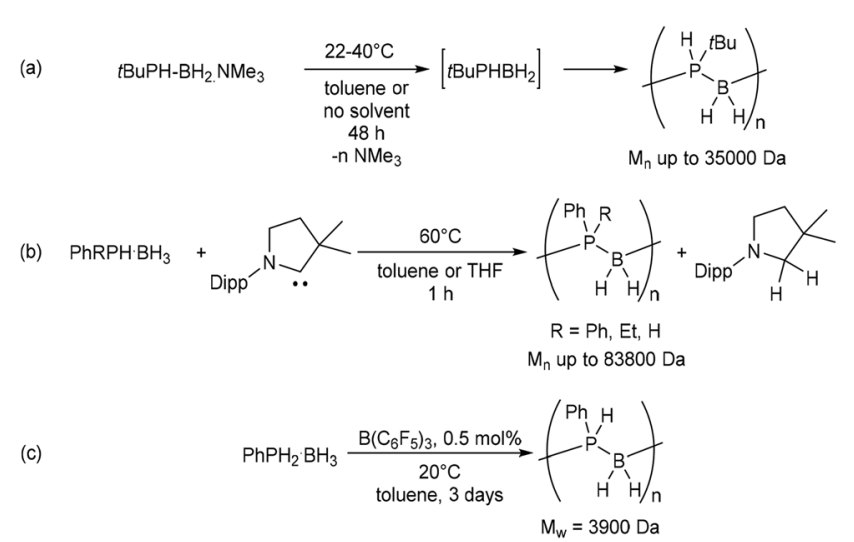

Scheme 1 (a) Metal-free head-to-tail polymerisation of tert-butylphosphinoborane. $^{12}$ (b) Cyclic alkyl amino carbene (CAAC)-mediated polymerisation of phosphine-boranes. ${ }^{13}$ (c) BCF-catalysed dehydropolymerisation of phenylphosphine-borane. ${ }^{14} M_{n}$ and $M_{w}$ values determined by GPC relative to polystyrene standards and, in the case of bimodal distributions, refer to the polymeric fraction only. 
phosphine-boranes to provide access to primary- and, previously unprecedented, secondary polyphosphinoboranes (Scheme 1b). ${ }^{13}$ Of particular relevance to the current work is the $\mathrm{B}\left(\mathrm{C}_{6} \mathrm{~F}_{5}\right)_{3}$ (BCF)-catalysed dehydropolymerisation of phosphine-borane and phenylphosphine-borane reported by Denis et al. in 2003 (Scheme 1c). ${ }^{14}$ This process was proposed to proceed via iterative borane transfer and dehydrocoupling steps involving a Brønsted-acidic phosphine-borane complex, $\left(\mathrm{C}_{6} \mathrm{~F}_{5}\right)_{3} \mathrm{~B} \cdot \mathrm{PPhH}_{2}$, as the active species. The obtained polymers were, however, of modest molecular weight and accompanied by a significant fraction of low molecular-weight oligomeric species.

Our own interest in this topic is motivated by the use of alkaline-earth (Ae) elements as non-toxic and inexpensive catalysts for the synthesis of inorganic polymers. ${ }^{15,16}$ Following previous investigations into Ae-mediated catalytic and stoichiometric amine-borane dehydrogenation and dehydrocoupling, ${ }^{17-26}$ we recently reported a series of $\beta$-diketiminate (BDI) supported alkaline-earth (Ae) phosphidoborane complexes, which are prepared by exposing diphenylphosphine-borane to readily accessible BDI-Ae hydride, alkyl, or amide precursors (Scheme 2a). ${ }^{27}$ Attempts to achieve complete phosphine-borane dehydrogenation were unsuccessful, however, and the use of super-stoichiometric quantities of phosphine-borane resulted in $\mathrm{BH}_{3}$ transfer to provide the phosphinodiboronate complex 2 and uncomplexed diphenylphosphine (Scheme 2a). The preference for these systems to undergo $\mathrm{BH}_{3}$ transfer rather than hydrideelimination was rationalised to be a consequence of the charge-dense Lewis acidic Ae-centre in conjunction with the soft phosphorus-centred Lewis base. In order to address this shortcoming, inspiration was drawn from the previously observed BCF-mediated hydride abstraction of [(BDI)Ae] amidoborane complexes (Scheme 2b). ${ }^{28,29}$ This transformation yielded hydridoborate derivatives $3 \mathbf{3 a}-\mathbf{c}$ with concomitant for- mation of the cyclic diborazane, $\left(\mathrm{Me}_{2} \mathrm{NBH}_{2}\right)_{2}$. It was anticipated that analogous BCF addition to phosphidoborane complexes $\mathbf{1 a}$ and $\mathbf{1 b}$ would provide a similar outcome, thus yielding oligomerisation products of the unsaturated diphenylphosphinoborane monomer.

\section{Results and discussion}

Addition of an equimolar quantity of BCF to a $\mathrm{d}_{8}$-toluene solution of the calcium complex 1a resulted in quantitative conversion to a new BDI-containing species, 4a (Scheme 3), whose $\gamma$-CH proton resonated at $\delta 4.85 \mathrm{ppm}$. Counter to expectation, the resultant ${ }^{11} \mathrm{~B}$ NMR spectrum comprised two broadened signals at $\delta-11.0$ and $-31.2 \mathrm{ppm}$ and no resonance corresponding to the anticipated $\left[\mathrm{HB}\left(\mathrm{C}_{6} \mathrm{~F}_{5}\right)_{3}\right]^{-}$anion was observed. Similarly, the ${ }^{31} \mathrm{P}\left\{{ }^{1} \mathrm{H}\right\}$ NMR spectrum showed no resonances corresponding to oligophosphinoboranes; ${ }^{7}$ instead, a single broad resonance centred at $\delta-1.43$ ppm was detected. Slow evaporation of a saturated toluene solution of the crude product at room temperature yielded single crystals, X-ray diffraction analysis of which provided the solid-state structure of the phosphinodiboronate complex, 4a (Fig. 1), in which the boron-bound hydrogens were located and refined without restraints. Solutions of compound $4 \mathbf{a}$ in $\mathrm{d}_{8}$-toluene or $\mathrm{C}_{6} \mathrm{D}_{6}$ were stable at room temperature and attempts to induce further reactivity by heating to $60{ }^{\circ} \mathrm{C}$ resulted in partial decomposition to the homoleptic complex $\left[(\mathrm{BDI})_{2} \mathrm{Ca}\right]^{30}$ and other unidentified species.

The BDI-complexed calcium centre of $\mathbf{4 a}$ is further coordinated by threefold $\mathrm{B}-\mu^{2}-\mathrm{H}-\mathrm{Ca}$ binding of a $\left[\left(\mathrm{C}_{6} \mathrm{~F}_{5}\right)_{3} \mathrm{~B} \cdot \mathrm{PPh}_{2} \cdot \mathrm{BH}_{3}\right]^{-}$anion and its coordination sphere is completed by an asymmetric $\eta^{6}$ interaction with the $\pi$-system of a neutral molecule of toluene. The toluene ligand is labile

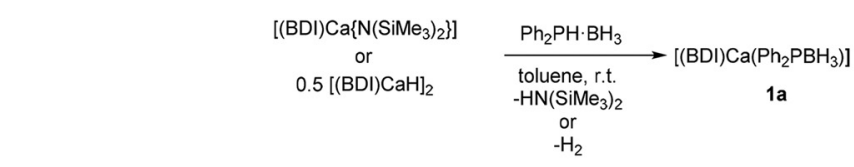

(a)

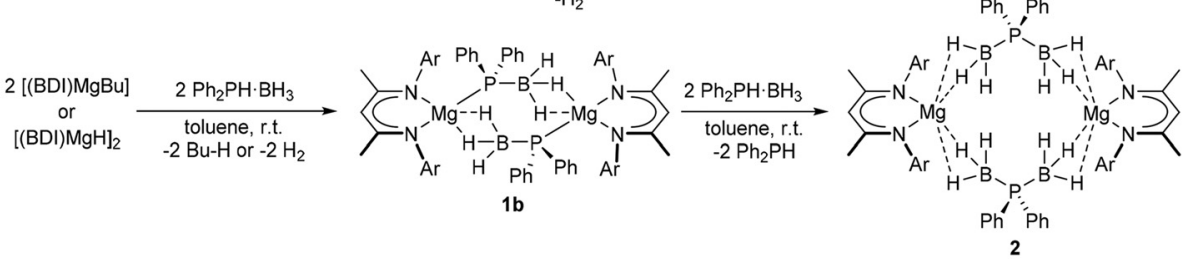

(b)

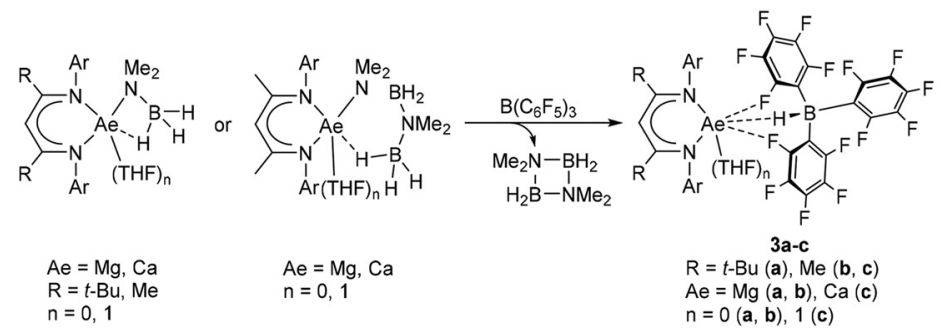

Scheme 2 (a) Synthesis and reactivity of Ae-phosphidoborane complexes, 1a and $1 b^{27}$ (b) BCF-promoted hydride abstraction of Ae-amidoborane complexes. ${ }^{28,29} \mathrm{Ar}=2,6$-di-isopropylphenyl. 


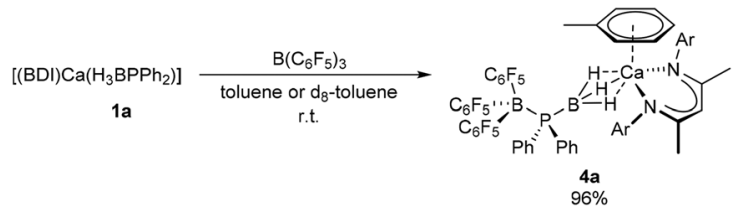

Scheme 3 Synthesis of compound 4a. Isolated yield shown, quantitative spectroscopic yield determined by NMR spectroscopy.

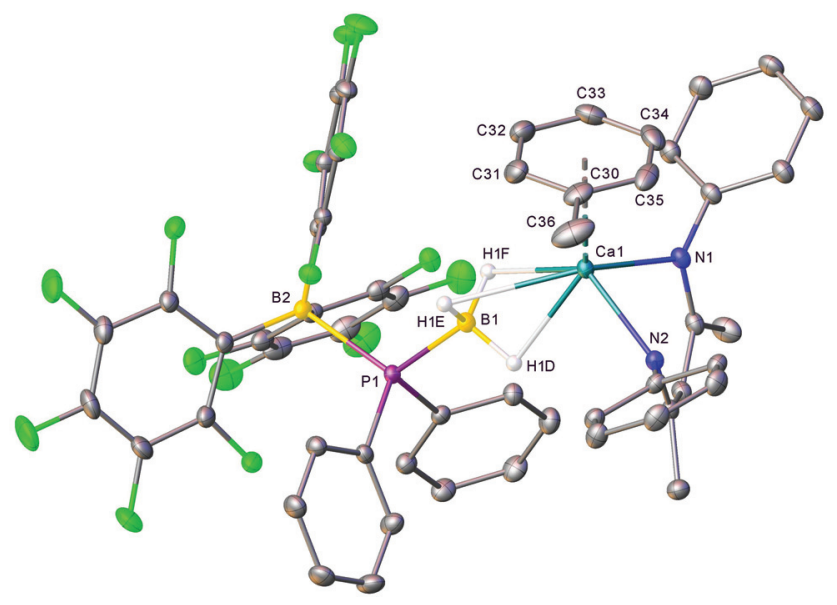

Fig. 1 X-ray crystal structure of compound 4a. Thermal ellipsoids displayed at the $30 \%$ probability level with iso-propyl groups and hydrogen atoms omitted except those bound to boron. Selected bond lengths ( $(\AA)$ and angles ( ${ }^{\circ}$ ): Ca1-N1 2.3147(14), Ca1-N2 2.2904(14), Ca1-C30 3.1365 (19), Ca1-C31 3.044(2), Ca1-C32 2.905(2), Ca1-C33 2.843(2), Ca1-C34 2.9055(19), Ca1-C35 3.0416(19), Ca1-(C30-C35 centroid) 2.6391(10), Ca1-(C30-C35 centroid plane) 2.6215(11), P1-C37 1.8343(17), P1-C43 1.8382(16), P1-B1 1.9469(18), P1-B2 2.1368(18), C49-B2 1.640(2), C55B2 1.640(2), C61-B2 1.639(2), C30-C31 1.388(3), C30-C35 1.396(3), C30-C36 1.502(3), C31-C32 1.389(3), C32-C33 1.381(3), C33-C34 1.379(3), C34-C35 1.383(3), N1-Ca1-(C30-C35 centroid) 110.05(5), N1-Ca1-(C30-C35 normal) 105.58(7), N2-Ca1-(C30-C35 centroid) 109.50(4), N2-Ca1-(C30-C35 centroid) 114.48(7), N2-Ca1-N1 84.76(5), C30-C31-C32 120.7(2), C33-C32-C31 120.3(2), C34-C33-C32 119.8 (2), C33-C34-C35 119.9(2), C34-C35-C30 121.2(2), C37-P1-C43 103.82(7), C37-P1-B1 105.99(8), C37-P1-B2 109.52(7), C43-P1-B1 106.29(8), C43-P1-B2 114.17(7), B1-P1-B2 116.06(7), C49-B2-P1 110.52(11), C49-B2-C55 111.11(13), C55-B2-P1 104.30(10), C61-B2-P1 102.97(11), C61-B2-C49 114.13(13), C61-B2-C55 113.02(13).

in solution such that when crystals of $\mathbf{4 a}$ were dissolved in $\mathrm{C}_{6} \mathrm{D}_{6}$, one equivalent of free toluene could be discriminated in the resulting ${ }^{1} \mathrm{H}$ NMR spectrum (Fig. S1 $\dagger$ ). The phosphinodiboronate anion displays near-perfect tetrahedral geometry at P1, a slightly flattened tetrahedron at B2 and essentially identical structural parameters to those of Lancaster and co-workers' lithium salt, $\left[\left\{\left(\mathrm{C}_{6} \mathrm{~F}_{5}\right)_{3} \mathrm{~B} \cdot \mathrm{PPh}_{2} \cdot \mathrm{BH}_{3}\right\} \mathrm{Li}\left(\mathrm{OEt}_{2}\right)_{3}\right]$, which was prepared by an analogous route. ${ }^{31}$ The contrasting P1-B1 (1.9469 (18) $\AA$ ) and P1-B2 (2.1368(18) A) bond lengths may be rationalised on simple steric grounds.

Although toluene adducts of barium are well established, the comparable ability of magnesium and calcium centres to bind neutral arenes has only been established very recently.
Charge-separated $[(\mathrm{BDI}) \mathrm{Ae}]^{+}[\mathrm{WCA}]^{-}$species $(\mathrm{WCA}=$ weakly coordinating anion: $\left[\mathrm{B}\left(\mathrm{C}_{6} \mathrm{~F}_{5}\right)_{4}\right]^{-}$or $\left.\left[\mathrm{Al}\left\{\mathrm{OC}\left(\mathrm{CF}_{3}\right)_{3}\right\}_{4}\right]^{-}\right)$coordinate arenes via $\eta^{2,3}$ or 6 interactions to give complexes of the type $[(\mathrm{BDI}) \mathrm{Ae} \cdot \text { arene }]^{+}[\mathrm{WCA}]^{-32-34}$ Compound 4 a provides, however, the first crystallographic characterisation of an unsupported interaction between a formally charge neutral calcium centre and an arene. The accommodation of the toluene ligand at the pseudo-tetrahedral metal-centre (for a space-filling representation of the crystal structure, see ESI, Fig. S24 $\dagger$ ) is facilitated by the disposition of the calcium centre, which projects some 1.3821(18) $\AA$ out of the mean plane defined by the BDI ligand. Ca1 is located 2.6391(10) $\AA$ from the toluene centroid but is asymmetrically coordinated with $\mathrm{Ca}-\mathrm{C}$ distances ranging from 2.843(2) $\AA$ (Ca1-C33) to 3.1365(19) Å (Ca1-C30). The average Ca-C distance of $2.979 \AA$ is, thus, only slightly longer than the comparable measurement in the charge separated cationic component of [(BDI) $\left.\mathrm{Ca} \cdot \mathrm{C}_{6} \mathrm{H}_{6}\right]^{+}\left[\mathrm{Al}\left\{\mathrm{OC}\left(\mathrm{CF}_{3}\right)_{3}\right\}_{4}\right]^{-}$(ca. $\left.2.93 \AA\right) .{ }^{33}$

Immediate assessment of an analogous reaction performed in $\mathrm{C}_{6} \mathrm{D}_{6}$ with the dimeric magnesium complex $\mathbf{1 b}$ was also indicative of the effectively instantaneous and quantitative generation of a phosphinodiboronate complex (4b, Scheme 4). The constitution of compound $\mathbf{4} \mathbf{b}$ was diagnosed by the emergence of a single new BDI ligand environment in its ${ }^{1} \mathrm{H}$ NMR spectrum and the appearance of a broad signal centred at $\delta$ $0.7 \mathrm{ppm}$ in the corresponding ${ }^{31} \mathrm{P}\left\{{ }^{1} \mathrm{H}\right\}$ NMR spectrum. In addition to the expected resonances at $\delta-10.4$ and $-36.7 \mathrm{ppm}$, however, a doublet signal at $\delta-22.0$ was observed to grow into the ${ }^{11} \mathrm{~B}$ NMR spectrum over the course of 16 hours. While this latter resonance, and the appearance of a further BDI-ligated species in the ${ }^{1} \mathrm{H}$ NMR spectrum, was readily attributed to the formation of the hydridoborate derivative, $\left[(\mathrm{BDI}) \mathrm{Mg}\left\{\mathrm{HB}\left(\mathrm{C}_{6} \mathrm{~F}_{5}\right)_{3}\right\}\right](3 \mathbf{b}),{ }^{28,29}$ this solution instability frustrated all attempts to isolate and structurally characterise compound $\mathbf{4 b}$.

Although the production of $\mathbf{3 b}$ is indicative of the successful abstraction of hydride from the phosphinodiboronate anion of $\mathbf{4} \mathbf{b}$, no signals corresponding to the expected oligomerisation products of $\left[\mathrm{Ph}_{2} \mathrm{P}=\mathrm{BH}_{2}\right]$ could be detected. ${ }^{7}$ Rather, in addition to the doublet signal of $\left[\mathrm{H}\left(\mathrm{BC}_{6} \mathrm{~F}_{5}\right)_{3}\right]^{-}$at $\delta$ $-22.0 \mathrm{ppm}$, the ultimate ${ }^{11} \mathrm{~B}$ NMR spectrum comprised three additional broad resonances at $\delta-10.2,-24.7$ and $-35.3 \mathrm{ppm}$ and the ${ }^{31} \mathrm{P}\left\{{ }^{1} \mathrm{H}\right\}$ NMR spectrum a broad multiplet at $\delta$ $-7.2 \mathrm{ppm}$ and a singlet at $\delta-42.7 \mathrm{ppm}$. Similarly, two differentiated $\mathrm{C}_{6} F_{5}$ environments were discriminated by ${ }^{19} \mathrm{~F}$ NMR spectroscopy, while the ${ }^{1} \mathrm{H}$ NMR spectrum evidenced a further, less symmetrical BDI-coordinated species (5), whose quantitative evolution was simultaneous to that of $\mathbf{3} \mathbf{b}$ and took place over the course of 16 hours at room temperature, or two hours at $40{ }^{\circ} \mathrm{C}$. Compound 5 was most clearly characterised by a broad pseudo-doublet at $\delta 3.05 \mathrm{ppm}$, which emerged with a similar ratio of ${ }^{1} \mathrm{H}$ NMR signal intensities to those assigned to $\mathbf{3 b}$. These spectroscopic features were eventually rationalised by X-ray diffraction analysis of single crystals of compound $\mathbf{5}$ (Fig. 2), obtained after removal of solvent and fractional crystallisation of the reaction products from a hexane/toluene 


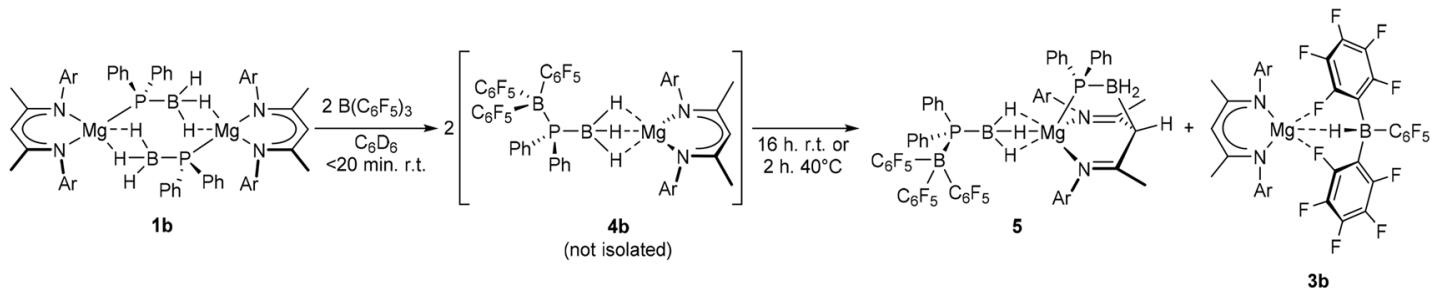

Scheme 4 Reaction of compound $1 \mathrm{~b}$ with BCF to provide compounds 5 and $3 \mathrm{~b}$ via $4 \mathrm{~b}$. Quantitative spectroscopic yields. Ar $=2,6$-diisopropylphenyl.

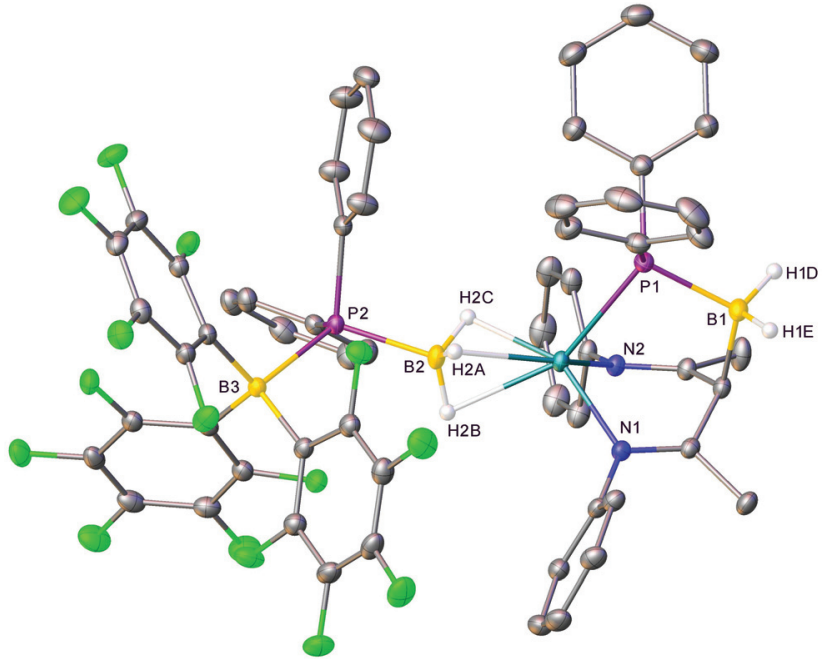

Fig. 2 X-ray crystal structure of compound 5. Thermal ellipsoids are shown at the $30 \%$ probability level. Hydrogen atoms except for $\mathrm{H} 3$ and those bound to boron are omitted for clarity, as are iso-propyl substituents. Selected bond lengths $(\AA)$ and angles $\left({ }^{\circ}\right)$ : P1-Mg1 2.5701(6), P1C30 1.8389(17), P1-C36 1.8358(17), P1-B1 1.9791(18), P2-C42 1.8403 (15), P2-C48 1.8339(16), P2-B2 1.9251(17), P2-B3 2.1100(16), Mg1-N1 2.0986(13), Mg1-N2 2.1057(13), N1-C2 1.2950(19), N2-C4 1.293(2), C1C2 1.502(2), C2-C3 1.494(2), C3-C4 1.488(2), C3-B1 1.726(2), C54-B3 1.649(2), C60-B3 1.636(2), C66-B3 1.655(2), C4-C5 1.504(2), C30-P1Mg1 121.60(6), C30-P1-B1 111.06(8), C36-P1-Mg1 119.50(6), C36-P1C30 97.43(7), C36-P1-B1 112.27(8), B1-P1-Mg1 95.60(6), C42-P2-B2 102.12(8), C42-P2-B3 117.18(7), C48-P2-C42 104.20(7), C48-P2-B2 106.70(8), C48-P2-B3 110.48(7), B2-P2-B3 115.06(7), N1-Mg1-P1 94.86(4), N1-Mg1-N2 92.73(5), N2-Mg1-P1 96.01(4), N1-C2-C1 123.85(14), N1-C2-C3 122.85(13), C3-C2-C1 113.27(13), C2-C3-B1 110.54(12), C4-C3-C2 119.41(13), C4-C3-B1 112.13(13), N2-C4-C3 122.49(13), N2-C4-C5 123.50(14), C3-C4-C5 114.00(13), C3-B1-P1 110.30(10), C54-B3-P2 110.68(10), C54-B3-C66 109.84(12), C60-B3P2 103.54(10), C60-B3-C54 113.11(12), C60-B3-C66 112.61(12), C66B3-P2 106.73(9), Mg1-B2-P2 163.63(10).

solvent system. As for $\mathbf{4 a}$, the hydrogen atoms attached to boron were located and refined freely.

Compound $\mathbf{5}$ consists of a mononuclear magnesium species ligated by a tripodal $N, P, N$ '-donor ligand and displays close $\mu-\mathrm{H}-\mathrm{Mg}$ contacts to the same $\left[\left(\mathrm{C}_{6} \mathrm{~F}_{5}\right)_{3} \mathrm{~B} \cdot \mathrm{PPh}_{2} \cdot \mathrm{BH}_{3}\right]^{-}$anion present in the $\mathrm{X}$-ray crystal structure of $\mathbf{4 a}$. The former anionic moiety is postulated to result from nucleophilic attack of the BDI $\gamma$-methine carbon centre upon the unsaturated phosphi- noborane monomer, $\left[\mathrm{Ph}_{2} \mathrm{P}=\mathrm{BH}_{2}\right]$, which is generated within the coordination sphere of magnesium by BCF-mediated hydride abstraction from $\left[\left(\mathrm{C}_{6} \mathrm{~F}_{5}\right)_{3} \mathrm{~B} \cdot \mathrm{PPh}_{2} \cdot \mathrm{BH}_{3}\right]^{-}$or $\left[\mathrm{Ph}_{2} \mathrm{P} \cdot \mathrm{BH}_{3}\right]^{-}$. Although Weller and co-workers' cationic rhodium complex $\left[\mathrm{Cp}{ }^{*} \mathrm{Rh}\left\{t \mathrm{Bu}_{2} \mathrm{P} \cdot \mathrm{BH}_{2} \cdot \mathrm{PMe}_{3}\right\}\right]\left[\mathrm{BAr}_{4}^{\mathrm{F}}\right]$, was similarly derived by interception of a phosphinoborane monomer generated by in situ phosphine-borane dehydrogenation, ${ }^{35}$ compound $\mathbf{5}$ is, to the best of our knowledge, the first example of a phosphinoborane trapped within the coordination sphere of a maingroup metal. Other kinetically stabilised transition-metal phosphinoborane complexes have been described by the groups of Scheer $^{36,37}$ and Bourissou, ${ }^{38}$ but were prepared by non-dehydrogenative metathesis and ligand exchange routes. Harder's calcium borylamide complex [(BDI)Ca(DippNBH $\left.\left.\mathrm{DH}_{2}\right)\right]$ bears comparison to compound $\mathbf{5}$ as an Ae-coordinated dehydrogenation product of a group 13-15 complex. ${ }^{25}$

Although examples of similar BDI $\gamma$-C-B bond formation are limited to a recent report by Jones and co-workers, ${ }^{39}$ the formation of $\mathbf{5}$ is clearly also reminiscent of the well documented reactivity of $[(\mathrm{BDI}) \mathrm{Ae}]^{+}$and $[(\mathrm{BDI}) \mathrm{AlMe}]^{+}$cations towards other unsaturated small molecules such as alkynes or $\mathrm{CO}_{2} \cdot{ }^{29,40,41}$ Consistent with the formulation of the tripodal anion as a bis-imine unit, the N1-C2 (1.2950(19) A) and N2-C4 (1.293(2) $\AA$ ) bond lengths of compound 5 are significantly shorter than those observed in unperturbed BDI anions. The geometry about C3 is also effectively tetrahedral, with $\mathrm{X}-\mathrm{C} 3-\mathrm{X}$ bond angles in the range of $110.5-119.4^{\circ}$. The $\mathrm{B} 1-\mathrm{P} 1$ bond (1.9791(18) $\AA$ ) is significantly longer than those typical of $B=P$ double bonds (1.763-1.913 $\AA$ ),${ }^{42-47}$ and even exceeds the dative $\mathrm{P}-\mathrm{BH}_{3}$ bonds of secondary phosphine-boranes (1.91-1.94 $\AA$ ), and is thus best described as an elongated single bond, consistent with the tetrahedral geometries at both phosphorus and boron. ${ }^{4,48-51}$ The C3-B1 bond $(1.726(2) \AA)$ is also elongated in comparison to the analogous $\gamma$-C-B bonds of Jones' compounds $(1.680(2)-1.697(3) \AA) .{ }^{39}$ The $\left[\left(\mathrm{C}_{6} \mathrm{~F}_{5}\right)_{3} \mathrm{~B} \cdot \mathrm{PPh}_{2} \cdot \mathrm{BH}_{3}\right]^{-}$ anion, however, remains geometrically similar to that of compound 4 a.

Several potential mechanisms were assessed theoretically by density functional theory (DFT) studies (BP86-D3(BJ)benzene/BS2//BP86/BS1) of the reaction between $\mathbf{1 b}$ and $\mathrm{BCF}$ that culminates in the formation of $\mathbf{3 b}$ and $\mathbf{5}$. Initial calculations addressed the direct abstraction of a hydride from the dimeric phosphidoborane, complex $\mathbf{1 b}$ (designated as pathway I; see ESI, Fig. S27†). This process ensues by disruption of a B- 
$\mu^{2}-\mathrm{H}-\mathrm{Mg}$ interaction and the formation of a B- $\mu^{2}-\mathrm{H}-(\mathrm{BCF})$ intermediate via a free energy barrier of $26.8 \mathrm{kcal} \mathrm{mol}^{-1}$. Although subsequent hydride abstraction, $\mathrm{Ph}_{2} \mathrm{P}=\mathrm{BH}_{2}$ elimination and interception steps were found to be kinetically facile and thermodynamically viable, this computed pathway (I) was discounted as it does not invoke the formation of the experimentally observed product, $\mathbf{4 b}$.

Incorporation of $\mathbf{4 b}$ into the mechanism necessarily requires insertion of a $\mathrm{BCF}$ molecule into one of the $\mathrm{Mg}-\mathrm{P}$ bonds of the dimeric starting complex $\mathbf{1 b}$ to form species $\mathbf{A}$ at $+6.7 \mathrm{kcal} \mathrm{mol}^{-1}$ (Fig. 3). Consideration of this requirement also raises a number of possibilities. Formation of a dative $\mathrm{P} \rightarrow \mathrm{B}$ bond significantly stabilises $\mathbf{A}$ to give intermediate $\mathbf{B}$ at $-14.2 \mathrm{kcal} \mathrm{mol}^{-1}$. Subsequent addition of a second molecule of BCF to $\mathbf{B}$ results in the cleavage of the $\mathrm{Mg}-\mathrm{P}$ bond and

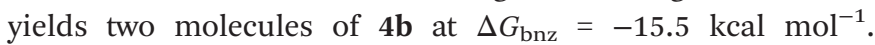
Alternatively, the second $\mathbf{M g}-\mathrm{P}$ bond in $\mathbf{B}$ can dissociate with the endergonic production of one molecule of $\mathbf{4} \mathbf{b}$ and one molecule of the monomeric phosphidoborane intermediate, $\mathbf{C}$ $\left(\Delta G_{\mathrm{bnz}}=+6.8 \mathrm{kcal} \mathrm{mol}^{-1}\right.$, left hand side of both Fig. $4 \mathrm{a}$ and b). The calculated molecular structure of $\mathbf{4 b}$ (see ESI, Fig. S31 and Table S5 $\dagger$ ) exhibits near co-planarity of the $\mathrm{Mg}$ centre with the BDI ligand, resulting in a sterically protected environment that obviates the possibility of a stable $\mathrm{Mg}$-arene solvent interaction, of the type observed for the analogous calcium complex, 4a. The DFT-optimised structure of an $\eta^{2}$-benzene adduct of $\mathbf{4 b}\left(\mathbf{4} \mathbf{b}^{\prime}\right)$ was found to reside $22.1 \mathrm{kcal} \mathrm{mol}^{-1}$ higher in energy than the unsolvated complex (see ESI, Fig. S25 $\dagger$ ).

C is relatively unencumbered, and one of its three boronbound hydrides can be readily intercepted by BCF to generate intermediate $\mathbf{D}, \Delta G_{\mathrm{bnz}}=-1.9 \mathrm{kcal} \mathrm{mol}^{-1}$ (left hand side of both Fig. $4 \mathrm{a}$ and b). D may also be formed directly from $\mathbf{4 b}$ by migration of the BCF moiety from the phosphorus centre to hydride of $\mathrm{B}^{\mathrm{a}}$. This was computed to occur with the complete dissociation of BCF from P. Once $\mathbf{D}$ has formed, however, the mechanism for formation of $\mathbf{3 b}$ (and 5) can diverge along two viable alternative trajectories, designated as pathways II and III, both of which invoke a significant degree of commonality (Fig. $4 \mathrm{a}$ and b).

The DFT-calculated Köhn-Sham frontier molecular orbitals of $\mathbf{D}$ (see ESI, Table $\mathrm{S} 4 \dagger$ ) reveal that the HOMO possesses significant P-lone pair character. As a result, $\mathbf{D}$ can either be intercepted by a further molecule of BCF in a marginally endergonic process to provide $\mathbf{E}, \Delta \Delta G_{\mathrm{bnz}}=3.8 \mathrm{kcal} \mathrm{mol}^{-1}$ (Fig. $4 \mathrm{a}$ ).
Subsequent progression along pathway II invokes hydride abstraction via transition state $\mathbf{T S}(\mathbf{E}-\mathbf{F})$ at $\Delta G_{\mathrm{bnz}}=+16.7 \mathrm{kcal}$ $\mathrm{mol}^{-1}$ to yield $\mathbf{F}$ at $\Delta G_{\mathrm{bnz}}=+14.2 \mathrm{kcal} \mathrm{mol}^{-1}$ in which a $\{(\mathrm{BDI})$ $\mathrm{Mg}^{+}$cation is loosely bound to a neutral BCF-stabilised phosphinoborane monomer $(\mathbf{G})$ and a $\left[\mathrm{HB}\left(\mathrm{C}_{6} \mathrm{~F}_{5}\right)_{3}\right]^{-}$anion via $\mu-\mathrm{F}$ interactions. $\mathbf{G}$ can then dissociate from $\mathbf{F}$ to provide the observed product $3 \mathbf{b}\left(\Delta G_{\mathrm{bnz}}(3 \mathbf{b}+\mathbf{G E})=-1.5 \mathrm{kcal} \mathrm{mol}^{-1}\right)$, the DFT-optimised structure of which is in good agreement with the previously published X-ray crystal structure of the magnesium hydridoborate product. ${ }^{28}$

Alternatively, the direct abstraction of a hydride from $\mathbf{D}$ can proceed via pathway III (Fig. 4b) and TS(D-3b) at $\Delta G_{\mathrm{bnz}}=$ $+7.2 \mathrm{kcal} \mathrm{mol}^{-1}$. The B-H distances in TS(D-3b) clearly show near-complete hydride transfer to the flattened tetrahedral boron centre, whilst the unsaturated $\mathrm{H}_{2} \mathrm{~B}=\mathrm{PPh}_{2}$ fragment remains bound to magnesium. Minor adjustments to the $\left[\mathrm{HB}\left(\mathrm{C}_{6} \mathrm{~F}_{5}\right)_{3}\right]^{-}$anion result in the endergonic elimination of free $\mathrm{H}_{2} \mathrm{~B}^{\mathrm{b}}=\mathrm{PPh}_{2}$ to provide $\mathbf{3 b}$ at $23.9 \mathrm{kcal} \mathrm{mol}^{-1}$ above $4 \mathbf{b}$ $\left(\Delta G_{\mathrm{bnz}}=+8.4 \mathrm{kcal} \mathrm{mol}^{-1}\right)$. Interestingly, $\mathrm{H}_{2} \mathrm{~B}^{\mathrm{b}}=\mathrm{PPh}_{2}$ can also be readily intercepted by a free $\mathrm{BCF}$ molecule to generate $\mathbf{G}$, $\Delta G_{\mathrm{bnz}}=-1.5 \mathrm{kcal} \mathrm{mol}^{-1}$, such that, from this point onwards, the course of the reaction to produce compound 5 is completely common to both computed pathways II and III.

The DFT calculated Köhn-Sham frontier molecular orbitals of free $\mathrm{H}_{2} \mathrm{~B}=\mathrm{PPh}_{2}$ displayed significant contributions from the $\pi$ - and $\pi^{*}$-molecular orbitals of the P-B bond (see ESI, Table S4 $\dagger$ ). In contrast, formation of the BCF-complex $\mathbf{G}$ results in de-population of the $\pi$-orbital and elongation of the P-B bond by $0.08 \AA$ to $1.96 \AA$. This bond length is comparable to $\mathrm{P}-\mathrm{B}$ single bonds observed in crystallographically characterised Lewis base- and Lewis acid-base stabilised phosphanylboranes. ${ }^{12,14,36,37,52-54}$ Whilst the calculated existence of an ortho-F-B donor-acceptor interaction in $\mathbf{G}$ provides some degree of a "push-pull" stabilisation ( $\mathrm{F}-\mathrm{B}$ distance $=$ $1.73 \AA$ ), the electron-withdrawing effect of the phosphoruscomplexed BCF moiety enhances the electrophilicity at boron. The calculated HOMO of $\mathbf{4 b}(-5.17 \mathrm{eV})$ involves a relatively exposed $\pi$-system delocalised across the BDI-ligand backbone. NBO charge analysis shows that the $\gamma$-methine carbon of the BDI ligand exhibits a significant negative charge $(-0.41)$ and can, hence, act as a nucleophile, attacking the electrophilic boron centre of the BCF-complex $\mathbf{G}$ via $\mathbf{T S}(\mathbf{G}-\mathbf{H})$ at $\Delta G_{\mathrm{bnz}}=$ $-0.9 \mathrm{kcal} \mathrm{mol} \mathrm{m}^{-1}$ to give $\mathbf{H}$ at $\Delta G_{\mathrm{bnz}}=-14.7 \mathrm{kcal} \mathrm{mol}^{-1}$. Although dissociation of BCF is computed to be endergonic by
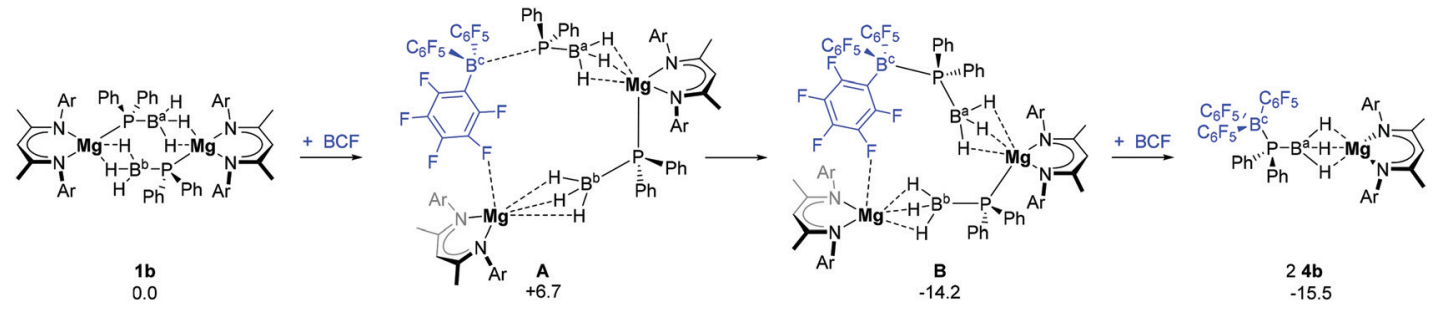

Fig. 3 DFT computed free energies (BP86-D3(BJ)-benzene/BS2//BP86/BS1), in kcal mol ${ }^{-1}$, for the reaction of $1 \mathrm{~b}$ with BCF to form two molecules of $\mathbf{4 b}$. Ar = 2,6-di-isopropylphenyl. 

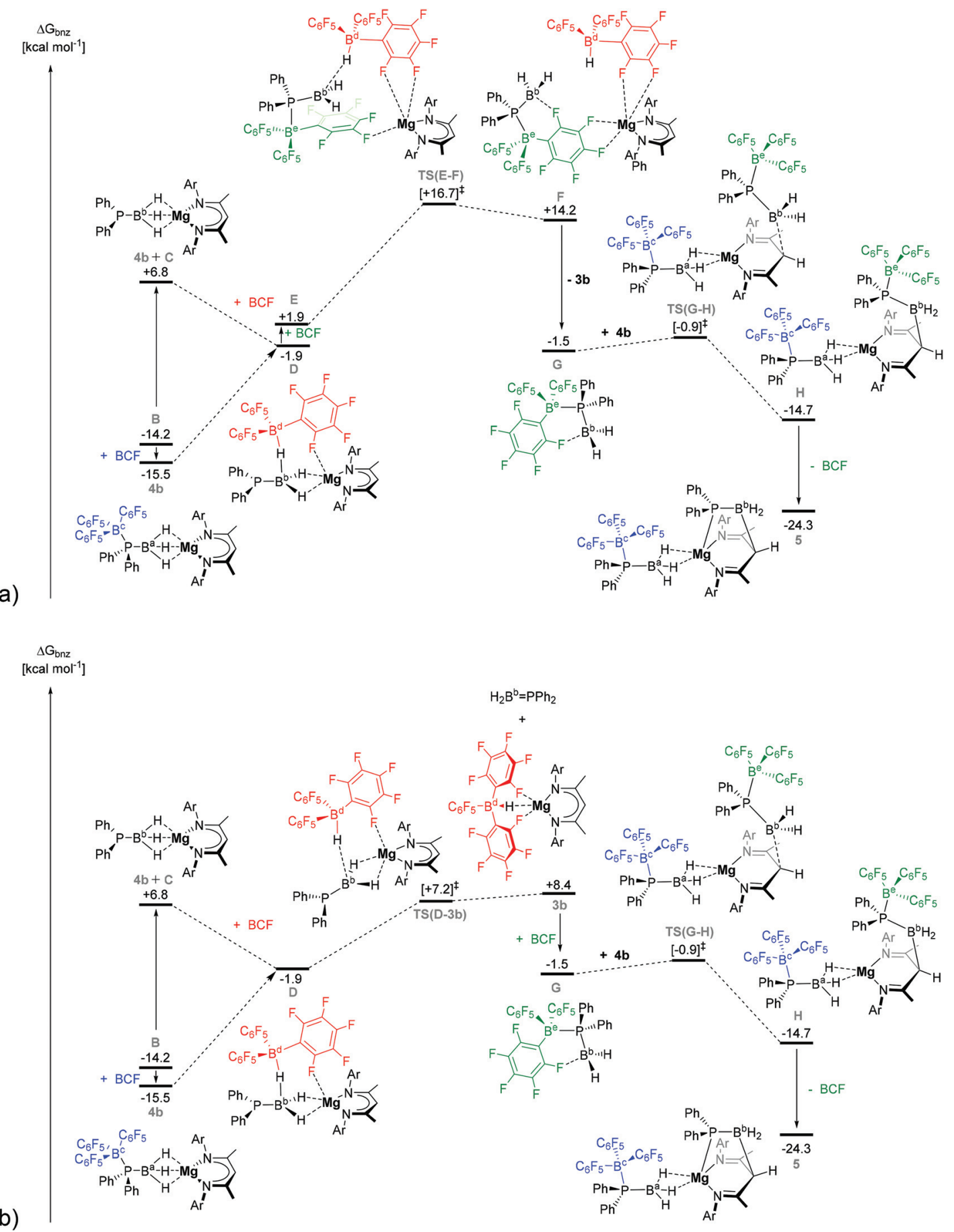

Fig. 4 DFT calculated free energy profile (BP86-D3(BJ)-benzene/BS2//BP86/BS1), in kcal mol ${ }^{-1}$, for the reaction of $4 \mathrm{~b}$ with BCF by (a) pathway II, and (b) pathway III. Ar = 2,6-di-isopropylphenyl.

$+17.0 \mathrm{kcal} \mathrm{mol}^{-1}$ with respect to $\mathbf{H}$, intramolecular formation of a $\mathrm{P}-\mathrm{Mg}$ dative bond is thermodynamically favoured. As such, stepwise $\mathrm{P}-\mathrm{B}$ cleavage and $\mathrm{Mg}-\mathrm{P}$ bond formation is exergonic, affording compound 5 at $\Delta G_{\mathrm{bnz}}=-24.3 \mathrm{kcal} \mathrm{mol}^{-1}$. The free energy barrier to $\mathbf{3 b}$ and $\mathbf{5}$ formation from $\mathbf{4 b}$ in pathway II is, therefore, computed to be $31.2 \mathrm{kcal} \mathrm{mol}^{-1}$ (via intermediates $\mathbf{E}$ and $\mathbf{F}$ ), whilst pathway III (via $\mathbf{3 b}$ ) is computed to be $23.9 \mathrm{kcal} \mathrm{mol}^{-1}$, the latter being $7.3 \mathrm{kcal} \mathrm{mol}^{-1}$ lower in free energy and most consistent with the reaction conditions.

Most known Ae-mediated catalytic processes have been shown to follow a trend of increasing reactivity on descending the group from magnesium to barium, as a result of increasing. polarisability, electropositivity and ionic radius. ${ }^{55-57}$ In this context, the apparent inertness of compound 4a towards formation of calcium analogues of $\mathbf{3 b}$ and $\mathbf{5}$ is intriguing. To this 
end, the mechanistic pathway for $\mathbf{4 a}$ formation and its onward reaction to the hypothetical calcium complexes $\mathbf{3} \mathbf{c}^{\prime}$ and $\mathbf{5}^{\prime}$ was also calculated (see ESI, Fig. S29 and S30†). Viable pathways for BCF-mediated hydride abstraction from the toluene-free intermediate $\mathbf{4 a}$ ' displayed similarities to pathways II and III for magnesium. Intermediate $\mathbf{4} \mathbf{a}^{\prime}$ was, however, located at $-4.7 \mathrm{kcal} \mathrm{mol}^{-1}$ with respect to $1 \mathrm{a}$ : some $26.7 \mathrm{kcal} \mathrm{mol}^{-1}$ higher in energy than the crystallographically characterised $\eta^{6}$ toluene complex $\mathbf{4 a}\left(\Delta G_{\text {tol }}=-31.4 \mathrm{kcal} \mathrm{mol}^{-1}\right)$. This latter species, therefore, may be viewed as an energetic sink, which precludes onward reactivity analogous to that observed for its magnesium analogue $\mathbf{4 b}$ such that transformation of $\mathbf{4 a}$ to $\mathbf{3} \mathbf{c}^{\prime}$ $+5^{\prime}$ is both kinetically unrealistic with a suggested free energy barrier of $37.9 \mathrm{kcal} \mathrm{mol}^{-1}$ and being almost thermoneutral.

\section{Conclusion}

In conclusion, addition of $\mathrm{B}\left(\mathrm{C}_{6} \mathrm{~F}_{5}\right)_{3}$ to the alkaline earth phosphidoborane complexes $\mathbf{1 a}$ and $\mathbf{1 b}$ initially results in $\mathrm{P} \rightarrow \mathrm{B}$ adduct formation to provide the monomeric phosphinodiboronate species, $\mathbf{4 a}$ and $\mathbf{4 b}$. In the solid state, the calcium complex 4a features an $\eta^{6}$-coordinated toluene molecule which, although labile in solution, was calculated to stabilise the compound towards onward reactivity. In contrast, arene solvent-coordination to the spectroscopically-detected magnesium analogue $\mathbf{4 b}$ was calculated to be endergonic, and this species transforms into the known $\left[\mathrm{HB}\left(\mathrm{C}_{6} \mathrm{~F}_{5}\right)_{3}\right]^{-}$derivative $\mathbf{3 b}$ and the $N, P, N^{\prime}$-ligated species $\mathbf{5}$. Crystallographic characterisation of 5 revealed it to be the product of $\mathrm{H}_{2} \mathrm{~B}=$ $\mathrm{PPh}_{2}$ interception by the nucleophilic BDI ligand backbone. Computational assessment of these processes suggests a mechanism involving BCF dissociation and subsequent hydride abstraction to generate the putative intermediate, $\mathrm{H}_{2} \mathrm{~B}=\mathrm{PPh}_{2}$. Key to the thermodynamic viability of the process are $\mu-\mathrm{F}-\mathrm{Mg}$ interactions; complexation of $\mathrm{H}_{2} \mathrm{~B}=\mathrm{PPh}_{2}$ by $\mathrm{BCF}$ was calculated to generate an electrophilic intermediate containing a $\mathrm{P} \rightarrow \mathrm{B}$ dative bond and a stabilising ortho$\mathrm{F}_{-} \mathrm{BH}_{2}$ interaction. These studies demonstrate the potential for cooperative main-group mediated reactivity in the dehydrogenation of phosphine-borane adducts. Whilst non-innocence of the BDI ligand utilised herein is a clear obstacle towards the use of this system in catalytic phosphine-borane dehydropolymerisation, these results will inform future efforts to develop improved and inexpensive catalysts for the synthesis of useful inorganic polymers.

\section{Conflicts of interest}

There are no conflicts to declare.

\section{Acknowledgements}

We thank the EPSRC for financial support through the Centre for Doctoral Training in Catalysis (EP/L016443/1) and research grant EP/R020752/1. I. M. thanks the University of Bristol for support and the Canadian Government for a C150 Research Chair. This research made use of the Balena High Performance Computing (HPC) Service at the University of Bath.

\section{References}

1 A. B. Burg and R. I. Wagner, J. Am. Chem. Soc., 1953, 75, 3872-3877.

2 J. R. Turner, D. A. Resendiz-Lara, T. Jurca, A. Schäfer, J. R. Vance, L. Beckett, G. R. Whittell, R. A. Musgrave, H. A. Sparkes and I. Manners, Macromol. Chem. Phys., 2017, 218, 1700120.

3 A. Schäfer, T. Jurca, J. Turner, J. R. Vance, K. Lee, V. A. Du, M. F. Haddow, G. R. Whittell and I. Manners, Angew. Chem., Int. Ed., 2015, 54, 4836-4841.

4 T. L. Clark, J. M. Rodezno, S. B. Clendenning, S. Aouba, P. M. Brodersen, A. J. Lough, H. E. Ruda and I. Manners, Chem. - Eur. J., 2005, 11, 4526-4534.

5 U. S. D. Paul, H. Braunschweig and U. Radius, Chem. Commun., 2016, 52, 8573-8576.

6 N. T. Coles, M. F. Mahon and R. L. Webster, Organometallics, 2017, 36, 2262-2268.

7 H. Dorn, R. A. Singh, J. A. Massey, J. M. Nelson, C. A. Jaska, A. J. Lough and I. Manners, J. Am. Chem. Soc., 2000, 122, 6669-6678.

8 D. Han, F. Anke, M. Trose and T. Beweries, Coord. Chem. Rev., 2019, 380, 260-286.

9 S. Pandey, P. Lönnecke and E. Hey-Hawkins, Eur. J. Inorg. Chem., 2014, 2456-2465.

10 H. Cavaye, F. Clegg, P. J. Gould, M. K. Ladyman, T. Temple and E. Dossi, Macromolecules, 2017, 50, 92399248.

11 M. A. Huertos and A. S. Weller, Chem. Sci., 2013, 4, 18811888.

12 C. Marquardt, T. Jurca, K. C. Schwan, A. Stauber, A. V. Virovets, G. R. Whittell, I. Manners and M. Scheer, Angew. Chem., Int. Ed., 2015, 54, 13782-13786.

13 N. L. Oldroyd, S. S. Chitnis, V. T. Annibale, M. I. Arz, H. A. Sparkes and I. Manners, Nat. Commun., 2019, 10, 1370 .

14 J. M. Denis, H. Forintos, H. Szelke, L. Toupet, T. N. Pham, P. J. Madec and A. C. Gaumont, Chem. Commun., 2003, 5455.

15 L. J. Morris, M. S. Hill, M. F. Mahon, I. Manners, F. S. McMenamy and G. R. Whittell, Chem. - Eur. J., 2020, 26, 2954-2966.

16 L. J. Morris, G. R. Whittell, J.-C. Eloi, M. F. Mahon, F. Marken, I. Manners and M. S. Hill, Organometallics, 2019, 38, 3629-3648.

17 D. J. Liptrot, M. S. Hill, M. F. Mahon and D. J. MacDougall, Chem. - Eur. J., 2010, 16, 8508-8515.

18 P. Bellham, M. D. Anker, M. S. Hill, G. Kociok-Köhn and M. F. Mahon, Dalton Trans., 2016, 45, 13969-13978. 
19 P. Bellham, M. S. Hill and G. Kociok-Köhn, Dalton Trans., 2015, 44, 12078-12081.

20 P. Bellham, M. S. Hill and G. Kociok-Köhn, Organometallics, 2014, 33, 5716-5721.

21 S. Harder, J. Spielmann and B. Tobey, Chem. - Eur. J., 2012, 18, 1984-1991.

22 J. Spielmann and S. Harder, Dalton Trans., 2011, 40, 83148319.

23 J. Spielmann, D. F. J. Piesik and S. Harder, Chem. - Eur. J., 2010, 16, 8307-8318.

24 J. Spielmann, M. Bolte and S. Harder, Chem. Commun., 2009, 6934.

25 J. Spielmann and S. Harder, J. Am. Chem. Soc., 2009, 131, 5064-5065.

26 J. Spielmann, G. Jansen, H. Bandmann and S. Harder, Angew. Chem., Int. Ed., 2008, 47, 6290-6295.

27 L. J. Morris, M. S. Hill, M. F. Mahon, I. Manners and B. O. Patrick, Organometallics, 2020, DOI: 10.1021/acs. organomet.0c00008.

28 M. D. Anker, M. Arrowsmith, R. L. Arrowsmith, M. S. Hill and M. F. Mahon, Inorg. Chem., 2017, 56, 5976-5983.

29 M. D. Anker, M. Arrowsmith, P. Bellham, M. S. Hill, G. Kociok-Köhn, D. J. Liptrot, M. F. Mahon and C. Weetman, Chem. Sci., 2014, 5, 2826-2830.

30 S. Harder, Organometallics, 2002, 21, 3782-3787.

31 A. M. Fuller, A. J. Mountford, M. L. Scott, S. J. Coles, P. N. Horton, D. L. Hughes, M. B. Hursthouse and S. J. Lancaster, Inorg. Chem., 2009, 48, 11474-11482.

32 J. Pahl, S. Brand, H. Elsen and S. Harder, Chem. Commun., 2018, 54, 8685-8688.

33 L. Garcia, M. D. Anker, M. F. Mahon, L. Maron and M. S. Hill, Dalton Trans., 2018, 47, 12684-12693.

34 A. Friedrich, J. Pahl, H. Elsen and S. Harder, Dalton Trans., 2019, 48, 5560-5568.

35 T. N. Hooper, A. S. Weller, N. A. Beattie and S. A. Macgregor, Chem. Sci., 2016, 7, 2414-2426.

36 K. C. Schwan, A. Y. Timoskin, M. Zabel and M. Scheer, Chem. - Eur. J., 2006, 12, 4900-4908.

37 U. Vogel, P. Hoemensch, K. C. Schwan, A. Y. Timoshkin and M. Scheer, Chem. - Eur. J., 2003, 9, 515-519.

38 A. Amgoune, S. Ladeira, K. Miqueu and D. Bourissou, J. Am. Chem. Soc., 2012, 134, 6560-6563.
39 D. D. L. Jones, A. J. R. Matthews and C. Jones, Dalton Trans., 2019, 48, 5785-5792.

40 J. Pahl, T. E. Stennett, M. Volland, D. M. Guldi and S. Harder, Chem. - Eur. J., 2019, 25, 2025-2034.

41 T. E. Stennett, J. Pahl, H. S. Zijlstra, F. W. Seidel and S. Harder, Organometallics, 2016, 35, 207-217.

42 A. N. Price and M. J. Cowley, Chem. - Eur. J., 2016, 22, 6248-6252.

43 S. J. Geier, T. M. Gilbert and D. W. Stephan, Inorg. Chem., 2011, 50, 336-344.

44 E. Rivard, W. A. Merrill, J. C. Fettinger and P. P. Power, Chem. Commun., 2006, 3800-3802.

45 R. A. Bartlett, H. V. R. Dias, X. D. Feng and P. P. Power, J. Am. Chem. Soc., 1989, 111, 1306-1311.

46 R. A. Bartlett, X. D. Feng and P. P. Power, J. Am. Chem. Soc., 1986, 108, 6817-6819.

47 X. D. Feng, M. M. Olmstead and P. P. Power, Inorg. Chem., 1986, 25, 4615-4616.

48 K. Izod, J. M. Watson, W. Clegg and R. W. Harrington, Inorg. Chem., 2013, 52, 1466-1475.

49 E. M. Pelczar, E. A. Nytko, M. A. Zhuravel, J. M. Smith, D. S. Glueck, R. Sommer, C. D. Incarvito and A. L. Rheingold, Polyhedron, 2002, 21, 2409-2419.

50 H. Dorn, E. Vejzovic, A. J. Lough and I. Manners, Inorg. Chem., 2001, 40, 4327-4331.

51 M. W. Day, B. Mohr and R. H. Grubbs, Acta Crystallogr., Sect. C: Cryst. Struct. Commun., 1996, 52, 3106-3108.

52 A. Adolf, U. Vogel, M. Zabel, A. Y. Timoshkin and M. Scheer, Eur. J. Inorg. Chem., 2008, 3482-3492.

53 A. Adolf, M. Zabel and M. Scheer, Eur. J. Inorg. Chem., 2007, 2136-2143.

54 A. Stauber, T. Jurca, C. Marquardt, M. Fleischmann, M. Seidl, G. R. Whittell, I. Manners and M. Scheer, Eur. J. Inorg. Chem., 2016, 2684-2687.

55 A. G. M. Barrett, C. Brinkmann, M. R. Crimmin, M. S. Hill, P. Hunt and P. A. Procopiou, J. Am. Chem. Soc., 2009, 131, 12906-12907.

56 C. Bellini, V. Dorcet, J. F. Carpentier, S. Tobisch and Y. Sarazin, Chem. - Eur. J., 2016, 22, 4564-4583.

57 B. Rösch, T. X. Gentner, H. Elsen, C. A. Fischer, J. Langer, M. Wiesinger and S. Harder, Angew. Chem., Int. Ed., 2019, 58, 5396-5401. 